\title{
Modelling cost-effectiveness and value of information in clinical trials to inform stop go decisions: results from the arctic study
}

\author{
Alison Smith ${ }^{1 *}$, Peter Hall ${ }^{2}$, John O'Dwyer ${ }^{1}$, Claire Hulme ${ }^{1}$, Dena Cohen ${ }^{1}$, Walter Gregory ${ }^{1}$ \\ From 3rd International Clinical Trials Methodology Conference \\ Glasgow, UK. 16-17 November 2015
}

\section{Background}

Trial interim analyses are traditionally based on an assessment of efficacy and safety. Early evaluation of cost-effectiveness and a quantification of the societal value of further research could provide additional information to inform stop-go decisions.

\section{Objective}

To assess the potential utility of early cost-effectiveness analysis (CEA) and value of information analysis (VOIA) within the context of a randomised clinical trial.

\section{Methods}

The ARCTIC trial randomised patients with previously untreated Chronic Lymphocytic Leukaemia to receive fludarabine, cyclophosphamide, mitoxantrone and low dose rituximab (FCM-miniR) or fludarabine, cyclophosphamide and rituximab (FCR; standard care). An interim efficacy analysis was conducted after 103 patients had completed therapy. CEA and VOIA were conducted using a Markov decision model, based on subsequent data from 200 patients.

\section{Results}

The trial was terminated early based on the results of the interim efficacy analysis. FCM-MiniR was not expected to be cost-effective over a lifetime horizon, producing an average lifetime cost saving of $£ 7,708$ and health loss of -0.67 QALYs. The VOIA, however, suggested a high value of further research due to uncertainty around key parameters. Whilst the CEA results support the interim efficacy findings, the VOIA results highlight the cost of

${ }^{1}$ University of Leeds, Yorkshire, UK

Full list of author information is available at the end of the article trial termination in terms of potential population net health loss (1,050 QALYs) by foregoing the opportunity to collect additional data.

\section{Conclusion}

Early evaluation of cost-effectiveness within clinical trials could provide useful information in addition to efficacy data for interim analyses. Future research proposals should incorporate CEA and VOIA at interim analysis, allowing research-value to influence stop-go decisions.

Authors' details

${ }^{1}$ University of Leeds, Yorkshire, UK. 'University of Edinburgh, Edinburgh, UK.

Published: 16 November 2015

doi:10.1186/1745-6215-16-S2-O27

Cite this article as: Smith et al:: Modelling cost-effectiveness and value of information in clinical trials to inform stop go decisions: results from the arctic study. Trials 2015 16(Suppl 2):O27.
Submit your next manuscript to BioMed Central and take full advantage of:

- Convenient online submission

- Thorough peer review

- No space constraints or color figure charges

- Immediate publication on acceptance

- Inclusion in PubMed, CAS, Scopus and Google Scholar

- Research which is freely available for redistribution
C Biomed Central 